\title{
Study on the insulation of HTS bushing at cryogenic temperature
}

\author{
W. J. Kim ${ }^{\text {a }}$, H. S. Shin ${ }^{\text {, }}$ T. S. Park ${ }^{\mathrm{c}}$, and S. H. Kim* a \\ ${ }^{a}$ Department of Electrical Engineering, Gyeongsang National University and ERI, Jinju, Korea \\ ${ }^{\mathrm{b}}$ Department of Mechanical Design Engineering, Andong National University, Andong, Korea \\ ${ }^{\mathrm{c}}$ Department of Aviation Mechatronics, Korea Aviation Polytechnic College, Sacheon, Korea
}

(Received 19 August 2013; revised or reviewed 16 September 2013; accepted 17 September 2013)

\begin{abstract}
In the development of high temperature superconducting (HTS) power machines, HTS bushing is one of core technologies. In particular, the insulation body with sheds and electrical insulation at cryogenic temperature have attracted a great deal of interest from the view point of the size, weight and efficiency of bushing. In this study, the electrical and mechanical characteristics of various insulators for body in liquid nitrogen $\left(\mathrm{LN}_{2}\right)$ were investigated. And the surface discharge distance, collar length of GFRP sheds were studied. To emit bubbles between sheds, the shape and arrangement of shed were studied. The shed structure for $60 \mathrm{kV}$ class HTS bushing were designed with regular arrangement.
\end{abstract}

Keywords : HTS bushing, Shed design, Surface discharge, Bubble

\section{1. 서 론}

전력케이블, 한류기, 변압기 등의 초전도 전력기기는 기존 전력기기의 크기 및 중량 감소, 효율 향상 등의 성능한계를 뛰어넘고 환경친화형 기기이므로 국내에서도 2001년부터 과학기술부 주관의 21세기 프론티어 연구개발 사업 중 차세대 초전도응용기술개발 사업(DAPAS)을 [1-3] 통하여 좋은 성과를 얻고 있다. 고온초전도 전력기기 개발에 있어 해결해야 될 요소기술로서는 교류손실 저감, 도체성능 향상, 냉각 기술, 고전압 절연설계 기술 및 부싱 (bushing) 기술 등이 있다. 그 중에서도 부싱의 개발은 초전도 전력기기의 운전을 위하여 기기의 내부로 전력을 인가하기 위해 반드시 개발되어야 할 핵심기술이다. 그러나 초전도 부싱은 현재 세계적으로 개발단계에 있으며 아직 상용화에는 이르지 못하고 있다.

일반적인 부싱의 구조는 [4] 도체를 절연체로 감싸 절연하는 구조이다. 초전도 부싱의 주요 절연요소는 기중 연면방전을 위한 상부 절연부와 관통파괴 절연을 위한 두께, 플랜지 하부의 기기내부의 액체질소 중 연면방전을 위한 하부 절연부로 구성된다. 상부 절연부는 기존의 일반 부싱의 설계방법을 이용하여 적용이 가능하나, 하부 절연부는 액체질소와 극저온기체가 존재하기 때문에 절연바디(body) 및 절연갓 (shed) 등의 재료기술과 더불어 극저온에서의 절연기술의 확립이 반드시 필요하다. 특히, 극저온 절연기술은 기기 및 부싱의 신뢰도, 컴팩트화 및 고성능화를 위해서 반드시 필요한 요소기술이다.

고온초전도체의 특성상 임계온도까지 온도를 내리기 위해서는 냉매인 액체질소의 사용은 불가피하다. 액체질소의 본질적인 절연 특성은 양호하나 증발잠열이 낮아 외부로부터 열 침입이나 퀜치 (quench)로 인해 기포(bubble) 가 발생하기 쉬워 절연성능의 저하가 우려되

* Corresponding author: shkim@gnu.ac.kr
고 있다 [5]. 그러므로 기기의 상용화를 위해서는 종래의 냉매만의 절연특성 외에 기포가 포함된 냉매의 절연성능에 관한 특성과 냉매의 냉각 통로를 확보하기 위한 검토가 불가피하다.

따라서 본 연구에서는 이와 같은 점을 감안하여 극저온에서 적용 가능한 유리섬유강화플라스틱 (GFRP) 절연재료를 대상으로 절연파괴 및 연면방전 특성을 연구하였다. 또한 기포의 발생량을 분석하여 기포를 포함한 냉매인 액체질소 중에서 절연재료의 절연특성 연구와 더불어 초전도 부싱 하부인 극저온부의 절연갓 형상 및 $60 \mathrm{kV}$ 급 절연갓 절연설계에 대하여 연구하였다.

\section{2. 실험장치}

부싱용 절연재료로서 GFRP, 실리콘 고무( $\mathrm{Si}$ rubber), 에틸렌플로필렌고무/실리콘 혼합물 $(\mathrm{EPDM} / \mathrm{Si})$, 방향성 폴리이미드(Nomex), 폴리 4 염화에틸렌(Teflon) 등을 시료로 사용하여, 절연파괴 및 기계적 특성을 조사하였다. 절연파괴용 전극계는 스테인레스강 상부 평판전극 $(25 \mathrm{~mm}$ $\Phi$ )과 하부 평판전극 $(75 \mathrm{~mm} \Phi)$ 이다. 전극이 설치된 시료는 습기를 제거하기 위하여 에틸 알콜로 세척하고, 건조기에서 건조시킨 후 GFRP 전극홀더(holder)에 고정시켜 절연파괴전압을 측정하였다. 한편, 각종 부싱용 절연재료의 기계적 특성은 인장만능시험기로 $77 \mathrm{~K}$ 및 $300 \mathrm{~K}$ 에서 측정되었다. 시료는 폭 $10 \mathrm{~mm}$, 길이 $110 \mathrm{~mm}$ 로 절단하여, 폭 $25 \mathrm{~mm}, 60 \mathrm{~mm}$ 게이지길이의 그립에 고정시켜 인장하였다.

Fig. 1에 연면방전용 전극계를 나타낸다. 연면방전용 전극계는 부싱의 실제 형상을 모의하기 위해 고전압 전극으로서 직경 $30 \mathrm{~mm}$ 인 구리 봉에 두께 $20 \mathrm{~mm}$ 인 GFRP 고분자를 감은 봉 형상이다. 연면길이는 200, 400 및 $600 \mathrm{~mm}$ 이며, 접지전극으로서 스테인레스강 테이프를 감아 사용하였다. 


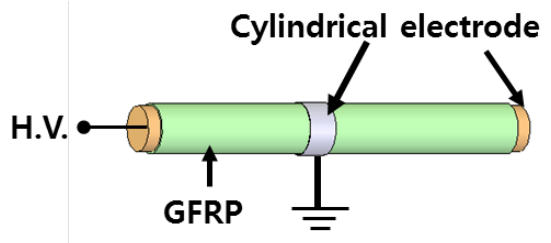

Fig. 1. Electrode system for surface discharge.

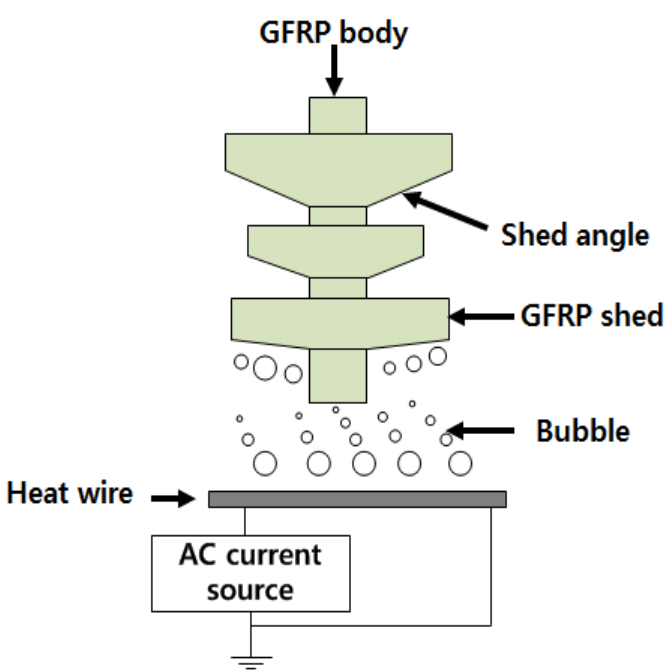

(a)

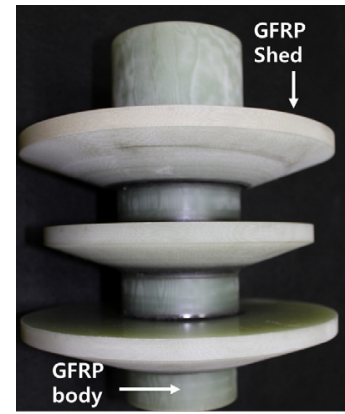

(b)

Fig. 2. The apparatus for bubble generation: (a) schematic of bubble generation, (b) The GFRP shed and body.

또한 Fig. 2(a)는 퀜치를 모의한 열기포 발생용 장치로서 하부에 열선을, 상부에 원형의 절연갓을 설치하여 측정하였다. 열선의 두께는 $0.6 \mathrm{~mm}$ 이고, 액체질소 중에서 저항율이 $2.3 \times 10^{-7}(\Omega \cdot \mathrm{m})$ 이다. 또한 절연갓의 직경은 $200 \mathrm{~mm}$ 이며 각도는 평판(0도), $5,10,20,40$ 도이다 (Fig. 2(b) 참조).

전극계는 저온용기 안에 배치시키고 내부에 액체질소를 충진하고 저온용기와 전극계를 충분히 냉각한 후 고전압을 인가하였다. 또한 기포 거동은 유리 저온용기를 사용하고 관측창를 통해서 사진촬영을 하였다.

실험에 사용된 고전압 전원은 최대전압 $100 \mathrm{kV}$ 의 AC 전원장치와 최대전압이 $400 \mathrm{kV}$ 이고 파형이 $1.2 / 50 \mu \mathrm{s}$ 인 표준임펄스 전원장치를 사용하였다. 전극계에 고전압을 약 $2 \mathrm{kV} / \mathrm{s}$ 의 속도로 절연파괴가 일어날 때까지 상승시켰으며, 임펄스 절연파괴 전압은 절연파괴 $70 \%$ 전압에서 $4 \mathrm{kV}$
단위로 인가전압을 계단식으로 상승시켜 절연파괴 및 연면방전전압을 측정하였다. 임펄스 파괴시험은 모두 (+)임펼스 전압으로 실시했다.

\section{3. 실험결과 분석 및 부싱 형상설계}

Fig. 3 는 동일한 조건에서의 액체질소 중 각종 절연재료의 (+) 임펄스 절연파괴 특성을 나타낸다. 그림에서 알 수 있는 바와 같이, GFRP, Nomex, Teflon, 실리콘 고무, $\mathrm{EPDM} / \mathrm{Si}$ 의 순서로 높은 것을 알 수 있다. $\mathrm{AC}$ 절연파괴 특성과 유사하게 $\mathrm{EPDM} / \mathrm{Si}$, 실리콘 고무를 제외하고는 거의 차이가 없는 좋은 절연재료인 것을 알 수 있다.

Fig. 4은 액체질소 중 각종 절연재료의 기계적 특성을 나타낸다. 그림에서 알 수 있는 바와 같이, GFRP는 인장하중, 항복응력, 파단강도 및 탄성률이 다른 재료에

비해 높은 값을 나타냈다. (Table1 참조)

따라서 본 연구에서는 극저온에서 기계적, 전기적으로 우수한 특성을 지닌 GFRP 절연재료를 대상으로 액체질소 중에서의 관통파괴 및 연면방전 특성에 대해 조사하고, 그 결과를 바탕으로 $60 \mathrm{kV}$ 급 부싱 극저온부 절연갓의 형상 및 절연설계를 하였다.

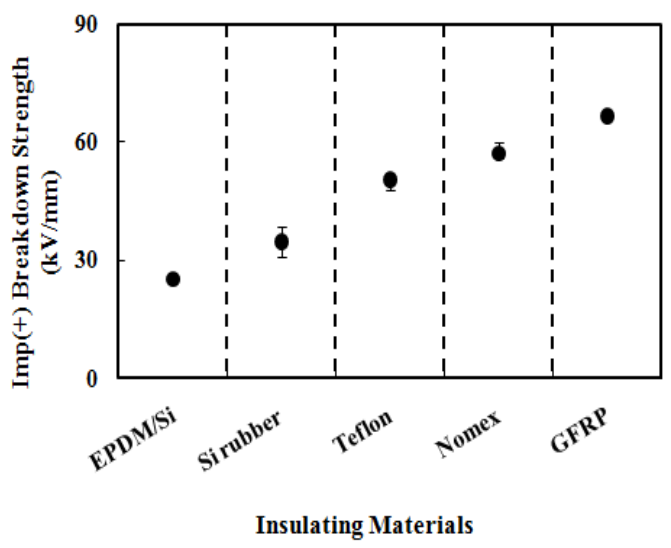

Fig. 3. $\operatorname{Imp}(+)$ breakdown characteristics of various insulators in $\mathrm{LN}_{2}$.

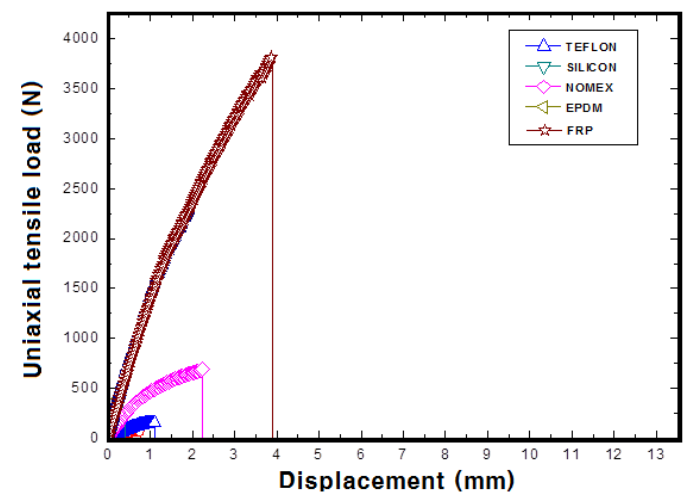

Fig. 4. Mechanical characteristics of various materials at $77 \mathrm{~K}$. 
TABLE I

MECHANICAL CHARACTERISTICS OF VARIOUS INSULATING MATERIALS.

\begin{tabular}{ccccc}
\hline Sample & $\begin{array}{c}\text { Yield } \\
\text { strength } \\
(\mathrm{MPa})\end{array}$ & $\begin{array}{c}\text { Tensile } \\
\text { load } \\
(\mathrm{N})\end{array}$ & $\begin{array}{c}\text { Stress } \\
\text { at break } \\
(\mathrm{MPa})\end{array}$ & $\begin{array}{c}\text { Young's } \\
\text { Modulus } \\
(\mathrm{MPa})\end{array}$ \\
\hline GFRP & 252.3 & 3,800 & 658 & 156.4 \\
Teflon & 63 & 153 & 71 & 56.1 \\
Si rubber & - & 275 & 34 & 55.5 \\
EPDM/Si & - & 383 & 27.5 & 55.4 \\
Nomex & 25.5 & 692 & 44 & 23.8 \\
\hline
\end{tabular}

초전도부싱 하부 극저온부의 길이는 액체질소 중에서의 GFRP 연면길이와 단열을 위한 극저온 기체질소의 높이를 함께 고려하여 결정된다. Fig. 5 에 액체질소 중에서 GFRP의 Weibull $0.1 \%$ 의 임펄스 최대 연면방전 전압의 GFRP 연면방전길이 의존성을 나타낸다. 그림에서 알 수 있는 바와 같이, GFRP 연면길이가 증가함에 따라서 연면방전 전압도 증가하는 경향을 나타내며 $\mathrm{V}_{\mathrm{s}}=21.376 \mathrm{~d}^{0.3782}\left(\mathrm{~V}_{\mathrm{s}}\right.$ : Weibull $0.1 \%$ 의 임펄스 최대 연면방전 전압, d:연면길이)의 실험식을 얻었다.

$60 \mathrm{kV}$ 급 부싱의 $\mathrm{BIL} 325 \mathrm{kV}$ 에 대한 연면거리 d는 (1) 식과 같다.

$$
d=\exp \left(\frac{\ln (B / L)-\ln 21.376}{0.3782}\right)
$$

따라서 절연갓이 없는 경우 극저온부의 GFRP 전체길이는 (1)식을 통해 $1,334 \mathrm{~mm}$ 가 되나, 여유치를 고려하여 $1,400 \mathrm{~mm}$ 로 하였다. 그러나 극저온부의 연면거리가 너무 길어서 이를 소형화하기 위해 절연갓의 칫수, 형상 등의 설계연구가 필요하다.

Fig. 6에 초전도 부싱의 각 절연요소별 절연특성을 나타낸다. 그림에서 알 수 있는 바와 같이, 액체질소의 절연내력 및 액체질소 중 $\mathrm{GFRP}$ 의 관통파괴전계는 각각 10 및 $10.5 \mathrm{kV} / \mathrm{mm}$ 이나 액체질소 중에서 $\mathrm{GFRP}$ 의 연면방전전계는 약 $2.5 \mathrm{kV} / \mathrm{mm}$ 이다. 액체질소 중에서 GFRP의 연면방전전계는 액체질소의 관통파괴전계 및 액체질소 중 $\mathrm{GFRP}$ 의 관통파괴전계보다 매우 낮다. 이것은 초전도기기의 운전 및 초전도 부싱 하부 액체질소 중의 절연갓 설계에 있어서는 연면방전 특성이 매우 중요함을 의미한다.

Fig. 7의 (a) 및 (b)에 규칙배치형 (Regular arrangement) 부싱 원형 절연갓의 각도에 따른 열기포의 거동 및 형상을 나타낸다. 그림 (a)에서 알 수 있는 바와 같이, 절연갓 각도가 0 도인 경우는 절연갓의 밑부분에 소기포(micro bubble)가 축적되어 갯수가 증가하고 시간이 경과함에 따라 소기포끼리 합쳐져 타원형의 거대 기포를 형성하여 부력에 의해 상승하여 빠져나가거나, 상부 절연갓으로 진입하여 절연갓 밑부분에 축적되는 경우도 종종 나타난다. 이러한 현상은 절연갓 각도를 증가할수록 축적되는 기포량은 감소하며, 상부 절연갓으로 진입하는 경우도 줄어든다. 절연갓 각도가 20 도 이상부터는 기포가 빠져 나가는 속도가 매우 빠르고, 상부 절연갓으로 진입하여 절연갓 밑부분에 축적되는 경우는 거의 나타나지 않는다.

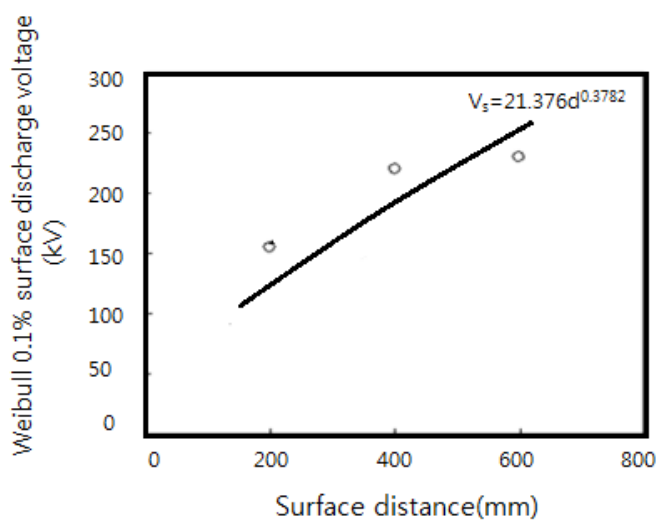

Fig. 5. GFRP surface length dependence of Weibull $0.1 \%$.

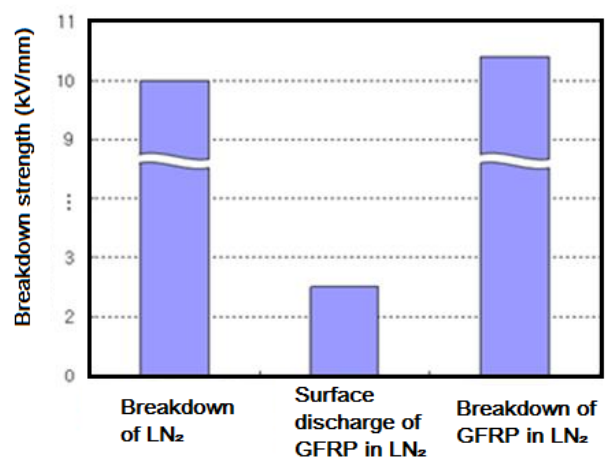

Fig. 6. Insulation characteristics of $\mathrm{LN}_{2}$ itself and GFRP in $\mathrm{LN}_{2}$.

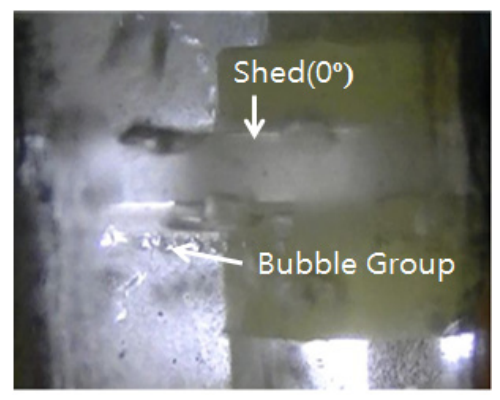

(a)

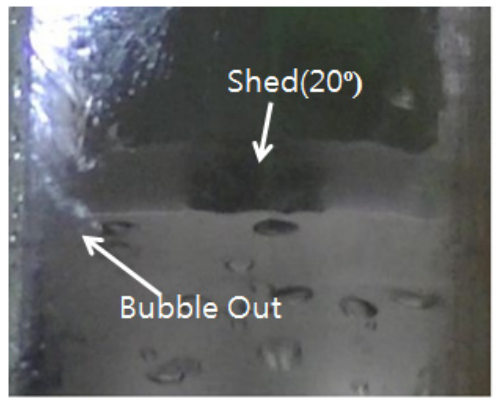

(b)

Fig. 7. Photographs of bubble behavior: (a) plane, (b) 20 degrees. 


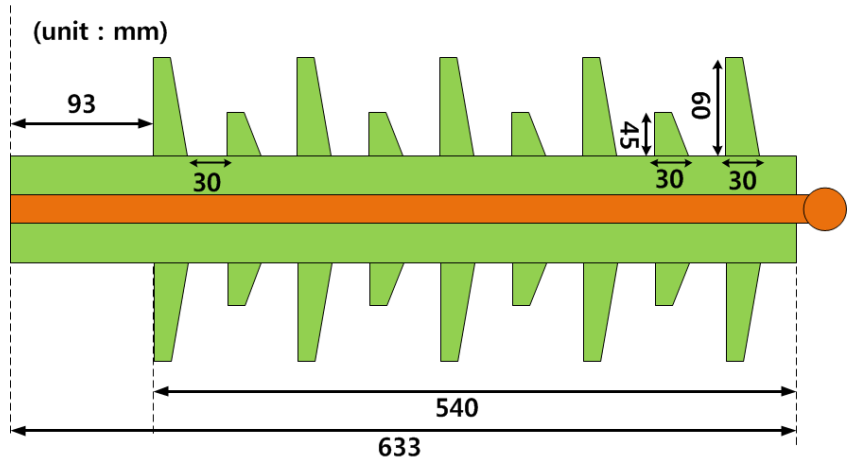

Fig. 8. Structure and design specifications of regular arrangement.

20도 이상부터는 매우 양호한 배출구조이나 절연갓 각도가 증가할수록 절연갓의 두께도 커져 절연갓의 개수가 줄어드는 문제가 발생한다. 예를들면, 동일한 부싱의 바디 길이에서 절연갓 각도를 40 도의 경우는 20 도의 경우보다 절연거리는 1.1 배 정도 증가하나, 절연갓의 두께가 1.8 배 정도 두꺼워지므로 절연갓의 개수가 줄어든다.

한편, 교대배치형의 경우는 규칙배치의 경우와 달리 절연갓의 크기가 작은 상부 절연갓으로 기포가 진입하거나 절연갓 밑부분에 축적되는 경우가 매우 적었으며, 각도가 20도 이상부터는 매우 양호한 배출구조를 나타내었다.

이상의 실험 결과를 바탕으로 교대배치형 (Alternative arrangement) $60 \mathrm{kV}$ 급 고온초전도 부싱의 형상을 설계하여 Fig. 8에 나타내었다. 극저온부 각도가 20도 이상부터는 매우 양호한 배출구조를 나타내었다. 즉 교대배치의 경우가 규칙배치의 경우보다 기포배출 및 절연갓간의 절연파괴전압 문제는 유리하나 절연갓의 개수는 많아졌다. 절연갓의 전체 연면길이는 규칙배치형과 동일하게 $1,400 \mathrm{~mm}$ 이다. 그러나, 극저온 기체질소 층은 $93 \mathrm{~mm}$ 여유를 더 두어 설치하여 총 절연바디의 길이는 $633 \mathrm{~mm}$ 이며, 절연갓은 20도로 총 9개를 설치하였다. 절연갓의 설치로 극저온부 절연바디의 전체길이가 절반 이상 축소되었고, 규칙배치형보다 기포배출도 효과적인 것을 알 수 있다.

\section{4. 결 론}

본 논문에서는 $60 \mathrm{kV}$ 초전도부싱 하부 극저온부의 절연갓 설계를 위하여 액체질소 중에서의 $\mathrm{AC}$ 및 임펼스 절연특성을 조사하였다. 얻어진 결과들을 요약하면 다음과 같다.

(1) 초전도 부싱용 바디 절연재료로는 극저온에서 절연파괴 특성뿐만 아 니라 기계적 특성이 우수한 GFRP가 가장 바람직하다고 할 수 있다. 그러나 보이드 문제 등의 제작상의 문제와 경제성의 문제 등은 실용 의 초전도 부싱 개발에 있어 검토해야 할 과제이다.
(2) GFRP 연면길이가 증가함에 따라서 연면방전전압도 증가하는 경향을 나타내며, Weibull $0.1 \%$ 의 임펄스 최대 연면방전압은 연면길이의 0.3782 승의 비례한다.

(3) 절연갓 각도가 20도 이상부터는 매우 양호한 배출구조이나, 절연갓 각도가 증가할수록 절연갓의 두께도 커져 절연갓의 개수가 줄어드는 문제가 발생한다.

(4) 기포배출 및 고전계 문제를 고려한 교대배치형 초전도 부싱 절연갓의 경우가 규칙배치형의 경우보다 총 길이가 약간 길어지나 기포의 배출은 양호한 구조이다.

(5) 교대배치형 $60 \mathrm{kV}$ 급 고온초전도 부싱 극저온부의 구조는 극저온 기체질소 층은 $93 \mathrm{~mm}$ 여유를 더 두어 설치하여 총 바디길이는 $633 \mathrm{~mm}$ 이며, 절연갓은 20도로 총 9 개를 설치하였다.

향후 미니모델 부싱을 제작하여 신뢰성을 확보하기 위한 시험평가를 할 예정이다.

\section{ACKNOWLEDGMENT}

This research was supported by Basic Science Research Program through the National Research Foundation of Korea (NRF) funded by the Ministry of Education, Science and Technology (No. 2011-0013667).

\section{REFERENCES}

[1] G. H. Lee, K. B. Park, J. Sim, Y. G. Kim, I. S. Oh, O. B. Hyun, and B. W. Lee, "Hybrid superconducting fault current limiter of the first half cycle non-limiting type," IEEE Trans. Appl. Supercond., vol. 19, no. 3, pp. 1888-1891, 2009.

[2] Y. S. Jo, K. S. Ryu, and M. W. Park, "1st Phase Results and Future Plan of DAPAS Program," IEEE Trans. Appl. Supercond., vol. 16, no. 2, pp. 678-682, 2006.

[3] D. W. Kim, H. M. Jang, C. H. Lee, J. H. Kim, C. W. Ha, Y. H. Kwon D. W. Kim and J. W. Cho, "Development of the 22.9-kV class HTS power cable in LG cable," IEEE Trans. Appl. Supercond., vol. 15, no. 2, pp. 1723 - 1726, 2005.

[4] T. Yamagiwa, Y. Kamata, Y. Yoshioka, and M. Hosokawa, "Dielectric characteristics of gas insulated bushings," IEEE Trans. Power Appar. and Systems, vol. PAS-100, no.6, pp.2746-2751, 1981.

[5] M. Hara, H. Koishihara, and K. Saita, "Breakdown behavior of cryogenic liquids in the presence of thermal bubbles under ramped voltage," IEEE Trans. Elect. Insulation, vol. 26, no. 4, pp. 685-691, 1991. 